\title{
Letter
}

\section{NONSTEROIDAL ANTI-INFLAMMATORY DRUGS AND GALLSTONE FORMATION}

\section{To the Editor,}

I have read with interest the letter of Buchanan et al (1) suggesting that gallstones might be less prevalent in rheumatoid arthritis. One hypothesis proposed by the authors for explaining this observation is that nonsteroidal anti-inflammatory drug (NSAID) treatment might be responsible for it. They illustrated this suggestion by citing the observation of Lee et al (2) that oral aspirin and other NSAIDS prevent cholesterol gallstone formation in the prairie dog. However, this was not confirmed in a more recent study conducted with aspirin both in the prairie dog and the hamster (3).

Actually, a study has been conducted in humans by a British/ Belgian gallstone study group (4). The results were published in 1988 in the Lancet. A questionnaire was sent to 82 patients taking part in a comparison of ursodeoxycholic acid, placebo and diet for prevention of gallstone recurrence after complete gallstone dissolution. Among the 12 regular users of NSAID, out of 75 who responded to the questionnaire, none had gallstone recurrence after 33 months of follow-up.

Another prospective study from Broomfield et al (5) has shown after 16 weeks of weight reduction treatment through dieting that 10 of 16 placebo-treated patients compared with only 3 of 13 aspirin $1300 \mathrm{mg}$-daily-treated patients developed gallstones. However, these data like those of Buchanan et al (1) show only a trend in favour of the hypothesis but are not statistically significant.

Nevertheless, it appears that other human studies seem to confirm that NSAID treatment probably plays a role in the low prevalence of gallstones apparently observed in patients suffering from rheumatoid arthritis.

\section{J.P. FAMAEY}

Department of Rheumatology and Physical Medicine, Hôpital Universitaire Saint-Pierre, University of Brussels, Belgium.

\section{REFERENCES}

1. Buchanan, W.W., Hernandez, L.A., Gerecz-Simon, E.M., Buchanan, H.M. Are gallstone less prevalent in rheumatoid arthritis? Clin Rheumatol 1991, 10, 339-340.

2. Lee, S.P., Carey, M.C., Lamont, J.T. Aspirin prevention of cholesterol gallstone formation in prairie dogs. Science 1991, 211, 14291430 .

3. Cohen, B.I., Mosbach, E.H., Ayyad, N., et al. Aspirin does not inhibit cholesterol cholelithiasis in two established animal models. Gastroenterol 1991, 101, 1109-1116.
4. Hood, K., Ruppin, D.C., Gleeson, D., Dowling, R.H. Prevention of gallstone recurrence by non-steroidal anti-inflammatory drugs. Lancet 2, 1988, 1223-1225.

5. Broomfield, P., Chopra, R., Sheinbaum, R. et al. Formation and prevention of lithogenic bile and gallstones during weight loss. Gastroenterol 1987, 92, 1721. 